\title{
Surgery for refractory mesial temporal lobe epilepsy: prognostic factors and early, rather than late, intervention
}

\author{
Cirurgia para epilepsia de lobo temporal mesial: fatores prognósticos e intervenção \\ precoce melhor que tardia
}

Carlos Alberto Mantovani Guerreiro

Professor Titular do Departamento de Neurologia da Faculdade de Ciências Médicas da Universidade de Campinas (UNICAMP), Campinas SP, Brazil.

\section{Correspondence:}

Carlos Alberto Mantovani Guerreiro Rua Tessália Viera de Camargo, 126 - CP: 6111

13083-970 Campinas SP - Brasil

E-mail:guerreiro@fcm.unicamp.br

\section{Conflict of interest}

There is no conflict of interest to declare.

Received 12 March 2012 Received in final form 16 March 2012 Accepted 23 March 2012

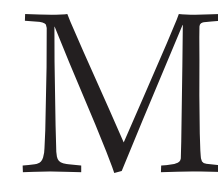

esial temporal lobe epilepsy (MTLE) is the most prevalent refractory epilepsy in adolescents and adults, and its pathologic hallmark is classic hippocampal sclerosis. There is the strongest level of evidence (Level A) to indicate surgical treatment for refractory unilateral MTLE ${ }^{1}$.

The study presented by Jardim et al. ${ }^{2}$ is important because it confirms the relationship between prognostic factors of surgery for unilateral MTLE and the pathologic findings. The best postoperative seizure control (i.e. Engel class 1) was associated with classic and severe patterns of hippocampal sclerosis (types $1 \mathrm{a}$ and $1 \mathrm{~b}$, respectively), as well as the presence of an initial precipitating injury ${ }^{2}$. The three patients with normal hippocampal findings were associated with poor outcome. This point is still controversial in the literature. In general, outcome is poorer in patients without hippocampal neuronal cell loss (no hippocampal sclerosis).

Nowadays, modern imaging with resonance techniques offers a very useful and safe way to check this point.

The study also reassures in that more than two thirds of the patients became seizure free for at least six months, which is considered a short follow-up. This outcome is compatible with the literature and it is considered a very successful outcome.

The concept of a medical refractory epilepsy patient is defined as the failure of adequate trials of two tolerated, appropriately chosen and used, antiepileptic drug schedules (either as monotherapies or in combination) to achieve sustained seizure freedom ${ }^{3}$. Therefore, it is possible to make the diagnosis of refractory MTLE relatively quickly.

Unfortunately, patients are operated on after 20 years of seizures, as confirmed by data in the article by Jardim et al. ${ }^{2}$. This astonishing fact occurs not only in Brazil, but also in other organized countries, such as the USA.

A recent study has shown that early referral for surgery is tremendously advantageous for the patients in order to avoid irreversible, disabling social, and psychological consequences of recurrent seizures, as well as minimizing the risk of premature death ${ }^{4}$.

We do hope that our fellow neurologists are aware of this important information and that all patients with refractory epilepsy are referred to an epilepsy center to determine if they might be candidates for surgery.

\section{References}

1. Engel J Jr, Wiebe S, French J, et al. Quality Standards Subcommittee of the American Academy of Neurology; American Epilepsy Society; American Association of Neurological Surgeons. Neurology 2003;60:538-547.

2. Jardim AP, Neves RSC, Caboclo LOSF, et al. Temporal lobe epilepsy with mesial temporal sclerosis: hippocampal neuronal loss as a predictor of surgical outcome. Arq Neuropsiquiatr 2012;70:319-324.

3. Kwan P, Arzimanoglou A, Berg AT, et al. Definition of drug resistant epilepsy: consensus proposal by the ad hoc Task Force of the ILAE Commission on Therapeutic Strategies. Epilepsia 2010;51:1069-1077.

4. Engel J Jr, McDermott MP, Wiebe S, et al. Early Randomized Surgical Epilepsy Trial (ERSET) Study Group. Early surgical therapy for drug-resistant temporal lobe epilepsy: a randomized trial. JAMA 2012;307:922-930. 